Language and Cognition 12 (2020), 343-359. doi:10.1017/langcog.2019.50

(C) UK Cognitive Linguistics Association, 2020. This is an Open Access article, distributed under the terms of the Creative Commons Attribution licence (http://creativecommons.org/ licenses/by/4.0/), which permits unrestricted re-use, distribution, and reproduction in any medium, provided the original work is properly cited.

\title{
Ranking Dutch intensifiers: a usage-based approach
}

\author{
MICHAEL RICHTER \\ Department of Computer Science, Natural Language Processing, Leipzig \\ University \\ A N D \\ ROELAND VAN HOUT \\ Centre for Language Studies, Radboud University Nijmegen
}

(Received 12 May 2019 - Revised 11 December 2019 - Accepted 11 December 2019)

\section{ABSTRACT}

The present approach estimates the strength of intensifiers in Dutch by computing their information values in a language corpus, that is, contextual information content (Cohen Priva, 2008; Piantadosi, Tily, \& Gibson, 2011) and Shannon Information (Shannon \& Weaver, 1948), to respectively explain the use value and the expressive value of intensifiers when they intensify a predicative adjective. Conflicting strength values help in understanding the high number of intensifiers commonly available in particular languages and the constant need for adding new ones. Our approach underlines the relevance of two measures of information content (IC) for ranking intensifiers: (i) IC in context: the more combinatorial or transitional options an intensifier has, the higher its contextual information content and consequently its use value; and (ii) IC in relation to all alternative intensifiers: the higher the surprisal value that the occurrence of an intensifier evokes, the higher its expressive value. We shall investigate the validity of these two measures by researching a large corpus of Dutch tweets and shall test whether the values of these two measures can predict the stacking order in sequences of intensifiers.

KEYW ORDS : intensifiers, strength, information value, corpus linguistics

\section{Introduction}

This paper addresses the use and expressive values of intensifiers in Dutch based on their usage profile in a language corpus. According to many studies (e.g., Tagliamonte, 2008, 2016; Hilte, Vandekerckhove, \& Daelemans, 2018; 
Vandekerckhove \& Vercammen, 2018), the appeal of intensifiers is not only their hyperbolic power, but also their social and emotional expressiveness. Languages often have a large and constantly changing collection of old and new intensifiers. Another salient property of intensifiers is that they can be stacked in sequences (e.g., Vandekerckhove \& Vercammen, 2018). Why is it that combinations like zo mega fucking goed (lit., 'so mega fucking good') are fairly common, while combinations such as mega zo fucking goed (lit., 'mega so fucking good') are, at best, awkward? We will argue that the usage profiles of intensifiers are related to the sequences in their stacks. Intensifiers can be used in combination with adverbs, adjectives, nouns, and verbs and in different constructions. We made the plain restriction to analyse intensifiers in a straightforward, predicative context, the predicate being an adjective, such as zij zijn echt zo fucking goed (lit., 'they are really so fucking good') and not in an attributive context such as het echt zo fucking goede boek (lit., 'the really so fucking good book'), to be sure that the intensifiers are all functioning as adverbials in direct relation to an adjective. By selecting only predicates we have ensured that the intensifier applies to the adjective. In addition, the subject of the predicative construction was a third person plural pronoun, referring to living organisms (+animate). Predicative adjectives can be intensified without exception, which makes this construction ideal for our analyses. Given specific discourses and contexts, it is possible to intensify even nongradable adjectives such as rectangular in order to express surprise, for instance when statements are made about persons - as it is the case in our test corpus like their faces are really rectangular. We shall argue that the strength of intensifiers can be estimated by their information values. Two types of information are relevant here:

(i) contextual information content ( $=\mathrm{IC}_{\mathrm{TRANS}}$ ), a form of conditional, Markov-like information, that is, a variant of conditional entropy. It is based on conditional probabilities, i.e., probabilities of transitions, and gives the amount of information that intensifiers convey within their (rightside) contexts. $\mathrm{IC}_{\text {TRANS }}$ represents the contextual use value of intensifiers and can be defined as given in (1) (Cohen Priva, 2008; Piantadosi, Tily, \& Gibson, 2011):

$$
I C_{T R A N S}=\mathbb{E}\left(-\log _{2}\left(P\left(W=w \mid C=c_{i}\right)\right)\right)
$$

$I C_{T R A N S}$ is the expectation value of the information that a word $w$ conveys in relation to its contexts. What counts as context is a matter of definition: contexts can be defined as n-gram co-occurrences of the target $w$, but also as syntactic contexts or even extra-sentential contexts (Levy, 2008).

(ii) local or paradigmatic information $\left(=\mathrm{IC}_{\mathrm{LOCAL}}\right)$, i.e., Shannon Information (Shannon \& Weaver, 1948), which refers to an expressive or surprisal value in competition with alternatives. This type is the information content of an 
intensifier in relation to its competitors, all alternative intensifiers. The formula is given in (2):

$$
I C_{L O C A L}=-\log _{2}(P(W=w))
$$

$\mathrm{IC}_{\text {LOCAL }}$ is the well-known Shannon Information and part of classical entropy estimation (Shannon \& Weaver, 1948), which estimates the average information content $H$ of a variable in general. It measures the paradigmatic surprisal of a word $w$, independent from its contexts.

These two concepts of information are linked to concepts in Dahl (2004) (see also ten ten Buuren, van de Groep, Collin, Klatter, \& de Hoop, 2018), i.e., the use value and expressive value of intensifiers: the use value $\mathrm{IC}_{\text {TRANS }}$ measures the usability in context, while the expressive value $\mathrm{IC}_{\mathrm{LOCAL}}$ measures the paradigmatic strength of intensifiers. Both types of information make concrete what surprisal of appearance means, within contexts or given a set of intensifiers in the mental lexicon, and lay the groundwork for a cognitively based explanation of strength of intensifiers through the attention that new intensifiers attract. Within surprisal theory (Hale, 2001), it is stated that surprisal is equal to information and proportional to the processing difficulty of a sentence (Levy, 2008): the higher the uncertainty and the surprisal of a message is, the higher its information value.

Intensifiers in Dutch, in the Netherlands and in Flanders, were the subject of several studies (Foolen, Wottrich, \& Zwets, 2016; ten Buuren et al., 2018; Vandekerckhove \& Vercammen, 2018), the research question being if and how the frequency and modernity/recency of intensifiers might correspond, and how their properties relate to their strength. In Foolen et al. (2016) a positive correlation is postulated between modernity and strength. The constant appearance of new intensifiers is explained by the decreasing strength of existing, current intensifiers: their content is diluted when they are used too commonly and too frequently (Foolen et al., 2016). This hypothesis was not supported by ten Buuren et al. (2018). In an empirical study with pupils of a Dutch secondary school, the authors found that both the estimated frequency and modernity of intensifiers correlate in a positive way to their estimated strength, but the problem in interpreting these results is that frequency and modernity are also revealed to be positively correlated. The pupils evaluated all of the frequent intensifiers as being fairly modern. A relevant aspect of these studies is that the concepts involved are seen as gradual properties (Richter $\&$ van Hout, 2017). The approach in this paper adapts the idea of graduality in strength. When strength can be approximated by the concept of information based on probabilities, we can use corpus data to obtain strength values. That means that usage-based probabilities define strength, whereas in ten Buuren 
et al. (2018) and Foolen et al. (2016) subjective ratings produced the strength values.

Information values may also model the establishment process of intensifiers in which semantic bleaching takes place: the intensifier's original, literal meaning is getting weaker until it is totally lost, leaving only the intensifying or amplifying function (Foolen et al., 2016) (see Sweetser, 1988, on bleaching as a process of meaning shift). For instance, the Dutch intensifier zeer 'very' and the German intensifier sehr 'very' are examples of common intensifiers that have lost their original meaning (see Dahl, 1979, on very). They have their roots in ninth-century Old High German and Old Saxon, i.e., sèr and serro, respectively, meaning 'with pain, painful, sad, hard' (compare Old English $s \bar{a} r$ 'painful'). In principle, there are no restrictions with regard to the original word class in creating new intensifiers, except that they are content words. Intensifiers can for instance be adjectives, such as geniaal 'ingenious' and goed 'good'; they can be nouns such as kanker 'cancer', tyfus 'typhus', and moker 'sledgehammer'; adverbs such as super 'super'; or verbs fuck(ing) 'fuck(ing)'. Bleaching of the original meaning goes hand in hand with a shift towards the adverbial class since intensifiers acquire the semantics of general (degree) adverbs.

We argue that, if intensifiers still possess the semantic properties of their original word classes, i.e., if bleaching is not completed, they tend to be positioned close to the adjective or attribute to be intensified and may not be the first element in a chain of intensifiers. As bleaching progresses, positional flexibility increases, as can be observed with established intensifiers.

According to Dahl (2004), the set of standard, established intensifiers does not exhibit a high diversity. That is to say, compared to the set of modern intensifiers, the standard set consists of a relatively small set of plain adverbs. In Dutch this set includes the intensifiers erg 'very', heel 'total', zeer 'very' (ten Buuren et al., 2018), and zo 'so'. These standard intensifiers do not have a high expressive value, but this is compensated by their high use value (Dahl, 2004): this means that they can be freely used in combinations with the word they intensify, in our case, predicative adjectives.

In the section that follows, we will argue that expressive value corresponds to the surprisal effect that intensifiers produce (described by Dahl, 2004, as informational value), given a set of alternative intensifiers. This assignment implies that recent, non-established intensifiers that we can classify as 'modern' produce a high amount of surprisal and thus have a high expressive value $\mathrm{IC}_{\mathrm{LOCAL}}$ since they are unexpected given the higher probabilities of occurrence of the established intensifiers.

Use value corresponds to the degree of establishment that we want to relate to the different words that are intensified by the intensifier in question. The most evident hypothesis is that an established intensifier has a high use value, 
but a low expressive value. Non-established intensifiers will have low use values and high expressive values, but we need to investigate how both measures interact in real data.

Another consequence of having strength values is the possibility to address the question of positional restrictions in stacks of intensifiers. In combinations of intensifiers, echt tends to occur on the leftmost position: echt buitengewoon lekker (lit., 'really extraordinary delicious'). In contrast, recent, nonestablished intensifiers such as tyfus seem to occur more often directly before the predicative adjective, when intensifiers are being combined (e.g., very fucking nice vs. fucking very nice). The pattern seems to be that stronger intensifiers would more likely occur near to the intensified adjective.

\section{Hypotheses}

The two types of information values can be used to formulate concrete hypotheses in relation to the expressive and use values of intensifiers:

H1: An established intensifier has a high use value and, consequently, a high IC TRANS; $_{\text {Tran }}$

$\mathrm{H} 2$ : An expressive intensifier has a high $\mathrm{IC}_{\text {LOCAL; }}$

H3: Intensifiers with high use values have lower expressive values. This implies that $\mathrm{IC}_{\text {TRANS }}$ and $\mathrm{IC}_{\mathrm{LOCAL}}$ are negatively correlated;

$\mathrm{H} 4$ : Intensifiers basically have a free stacking order, but the more established an intensifier is, the more it tends to occur in the leftmost position.

The rationale of the last hypothesis is that an established intensifier may be helpful in interpreting a following word or phrase as another intensifier, if that word or phrase is not the predicative adjective. In this way, an established intensifier paves the way for a less established intensifier. New intensifiers are less known than established intensifiers and seem to have less positional and interpretational flexibility. They tend to occur directly in front of the predicative adjective. This implies that there is a preference for ICs to increase their $\mathrm{IC}_{\text {TRANS }}$ and $\mathrm{IC}_{\text {LOCAL }}$ values in a stack of intensifiers.

\section{The corpus data}

Our study is based on a Twitter corpus, as described in Grondelaers, van Hout, and van Halteren (2017). It is a sample from the large Twitter database available for Dutch. Twitter is an emblematic example of informal computer-mediated communication (CMC), with the prototypical features of digital writing (Crystal, 2001). One of the principles of CMC is to use expressive forms and/or signs to compensate for the absence of facial 
expressions and intonation (Androutsopoulos, 2011). Intensifiers are a core category of lexical expressive markers that are used abundantly in CMC communication (Hilte et al., 2018).

A selection was made of tweets containing a full subject pronoun referring to the third person plural in combination with adjacent verb forms. Dutch has reduced pronouns with only a referential function, but the full pronouns additionally have a strong emphatic effect. Grondelaers et al. (2017) explored a large twitter corpus (TwiNL copus; Tjong Kim Sang \& van den Bosch, 2013) to extract 14,658 Tweets with a full third person plural pronoun. The standard form of this pronoun is $z i j$ 'they', but the substandard variant hun 'them', in fact the object form, is increasingly taking over the subject function in spoken Dutch (Grondelaers et al., 2017). As half of the 14,658 occurrences were the substandard variant, this finding shows that CMC communication often triggers informal, spoken forms. These tweets happened to contain many intensifiers, and in selecting the tweets we were permissive in allowing all sorts of intensifiers, the decisive criterion being that the word in question was meant to increase the intensity of the adjective. We made a subcorpus of those tweets containing predicative adjectives with preceding intensifiers. It means that all the utterances contained the copula zijn 'be', being the third person plural verb form zijn 'are'. The total number of occurrences was 3692, of which 3177 had 1 intensifier (86.1\%), 490 had 2 intensifiers (13.3\%), and 25 had three intensifiers $(0.6 \%)$, giving a grand total of 4232 intensifiers. That means that $28.9 \%$ of the selected tweets contained minimally one intensifier. This outcome convincingly indicates that we selected a context which triggers a productive usage of intensifiers. This conclusion is corroborated by the result that we counted 115 unique intensifiers. In this classification, repetitions were counted as one and the same intensifier. Orthographic variants were subsumed under their original form. Forms like eeecht, zoooo, and wauuw were respectively assigned to their basic forms, echt, zo, and wauw.

The predicative adjectives are preceded by between one and three intensifiers. We will refer to these positions as INT1, INT2, and INT3, respectively, where INT3 is the position directly preceding the adjective. The most frequent intensifiers were echt 'really' (2079 occurrences; 49.1\%), zo 'so' (938; $22.2 \%)$, fucking 'fucking' (195; 4.6\%), super 'super' (160;3.8\%), and heel 'totally' (116; 2.7\%).

A considerable number of intensifiers - 56 (48.7\%) of the 115 unique intensifiers - such as tyfus 'typhus', irritant 'irritating', gruwelijk 'horrible', overdreven 'overdone', knetter 'crackling', hartstikke 'very', fake 'fake', boem 'boom' and vetmelig 'fat', are hapax legomena, i.e., occurring just once. Modern ones such as fake 'fake' and boem 'boom' apparently are mixed up with oldfashioned ones like hartstikke 'very' (for this classification, see ten Buuren et al., 2018). 
In Vandekerckhove and Vercammen (2018), the occurrences of 24 intensifiers were investigated in a Flemish chat corpus ( 2 million words). Half of these words do not occur in our corpus, showing clear differences in the use of intensifiers between Dutch in the Netherlands and Dutch in Flanders. A strong regional differentiation is found even within Flanders. The two most frequently used intensifiers there are the same as our two most frequent ones (echt 'really', and zo 'so'), although in the opposite order. The enormous productivity of the set of intensifiers is illustrated by the list of 200 different intensifiers presented in ten Buuren et al. (2018) for Dutch in the Netherlands.

\section{Analysis and results}

We computed $\mathrm{IC}_{\text {TRANS }}$ and $\mathrm{IC}_{\text {LOCAL }}$ for all 115 intensifiers. In 'Appendix 1' we give the $\mathrm{IC}_{\text {TRANS }}$ values. We based $\mathrm{IC}_{\text {TRANS }}$ on the probability transition matrix, independent of their position, in relation to all predicative adjectives. The $\mathrm{IC}_{\mathrm{LOCAL}}$ values, again independent of their position in a stack of intensifiers, are listed in 'Appendix 2'. 'Appendix 1' contains values from 0 (meaning that there is only one unique combination between this intensifier and a following adjective) to 1.971 (gewoon 'plainly'). 'Appendix 2' contains values between a minimum of 1.025 (echt 'really'), meaning the minimal surprisal value, and 12.047 , meaning a maximal surprisal value. The transition probabilities of the intensifiers echt 'really', and tyfus 'typhus' may give an idea of how $\mathrm{IC}_{\text {TRANS }}$ works. The latter intensifier has a low $\mathrm{IC}_{\text {TRANS }}$ since it combines solely with one element, the probability of that particular element being 1 , and thus $\mathrm{IC}_{\mathrm{TRANS}}=0$. In contrast, there are 2079 occurrences of $e$ cht 'really' in our corpus, and this intensifier has the highest number of co-occurring predicative adjectives, that is, 187 . Consequently, the transition probabilities are small and the uncertainty is high. $\mathrm{IC}_{\text {TRANS }}$ should be also high: it is 0.570 . This outcome is obviously lower than the outcome for erg 'very', which is 1.827 , although this intensifier combines only with 17 elements. How can that be? In Table 1 we give the beginning of the transition vector for echt 'really'. Part of the transition vector of erg 'very', is given in Table 2.

Tables 1 and 2 both show a high transitional probability for the adjective goed 'good', but it is extremely high in the case of echt 'really': 0.42. Consequently, the IC value decreases substantially because it gives a fairly high certainty about the following context: in $42 \%$ of the occurrences it is the

T A B LE 1. Transition probabilities of echt 'really'

\begin{tabular}{lllllll}
\hline & aardig & abnormal & afschuwelijk & allebei & asocial & goed \\
\hline echt & 0.000934 & 0.000467 & 0.000467 & 0.000467 & 0.000934 & 0.42 \\
\hline
\end{tabular}


RICHTER AND VAN HOUT

TAB LE 2. Transition probabilities of erg 'very'

\begin{tabular}{lllllll}
\hline & aardig & actief & actueel & enthousiast & erg & goed \\
\hline $\operatorname{erg}$ & 0.02 & 0.02 & 0.02 & 0.06 & 0.02 & 0.22 \\
\hline
\end{tabular}

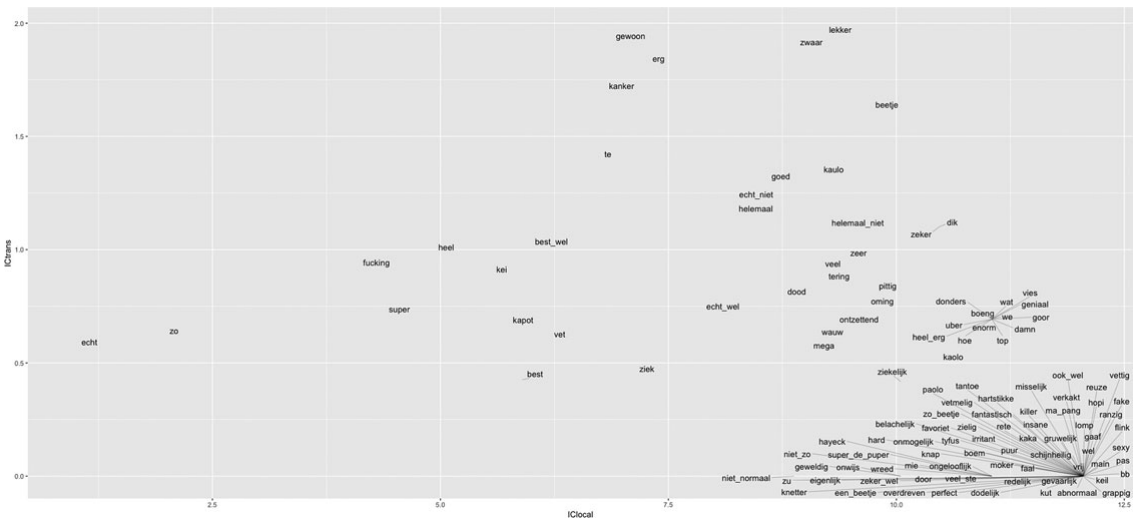

Fig. 1. Scatterplot of variables $\mathrm{IC}_{\text {TRANS }}$ and $\mathrm{IC}_{\mathrm{LOCAL}}$. The exceptional position of echt 'really' and $z o$ 'so' is clearly visible. The point cloud at the bottom right consists of intensifiers with

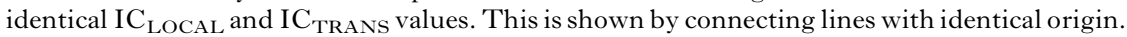

adjective goed 'good'. A similar case is zo 'so'. There are 940 occurrences of $z o$ in the corpus, but in roughly $46 \%$ of these it intensifies the adjective goed 'good'. Consequently, although zo co-occurs with several intensifiers, in almost half of its occurrences it precedes the adjective goed 'good', which drastically reduces its transitional uncertainty $\mathrm{IC}_{\text {TRANS }}$ value. In contrast, erg 'very' only combines with goed 'good' with a probability of 0.22 , which increases the transitional uncertainty and thus increases the $\mathrm{IC}_{\mathrm{TRANS}}$ of this intensifier. However, given our Twitter corpus, we need to consider the possibility of corpus-specific IC effects. We shall return to this point later.

How do the two IC measures correlate? The expectation is that the measures are different, as they measure two different forms of information, but they also have overlapping properties. Their correlation turns out to be negative, $r=-0.627, p=.000$, Spearman's rho even being higher, $\rho=-0.835, p=$ .000 , an outcome that suggests a non-linear pattern of association. The scatterplot is given in Figure 1.

On the right part of the scatterplot we see a pattern that is fairly linear, but there is a clear set of violations with intensifiers having very low $\mathrm{IC}_{\mathrm{LOCAL}}$ values in combination with medium $\mathrm{IC}_{\mathrm{TRANS}}$ values. The intensifiers echt 'really' and zo 'so' do not fit the overall pattern at all since these intensifiers also carry low $\mathrm{IC}_{\mathrm{TRANS}}$ as low $\mathrm{IC}_{\mathrm{LOCAL}}$ values. 
Can we compare the outcomes of our two IC measures with the outcome in the two empirical studies on Dutch (ten Buuren et al., 2018; Vandekerckhove \& Vercammen, 2018)? In ten Buuren et al. (2018), secondary-school children estimated the frequency and modernity of a set of intensifiers. There is an overlap of 16 intensifiers. The correlations between the $\mathrm{IC}_{\mathrm{TRANS}}$ and the two estimated values are not significant. The correlations for the $\mathrm{IC}_{\mathrm{LOCAL}}$ on the other hand are significant, $-0.508(p=.044)$ for estimated modernity, and $0.587(p=.017)$ for estimated frequency. These correlations substantiate the validity of our $\mathrm{IC}_{\mathrm{LOCAL}}$ measure.

For the outcomes of Vandekerckhove and Vercammen's study (2018), we observe the same pattern. Here, the frequencies of 24 intensifiers in a chat corpus for three regions in Flanders are given. There is an overlap of 12 intensifiers with the set in our study. There are, however, no significant correlations with IC $\mathrm{TRANS}_{\text {. }}$

There are three (near-)significant correlations with $\mathrm{IC}_{\mathrm{LOCAL}}$ : $-0.690(p=$ $.013)$, West Flanders; $-0.528(p=.078)$, Brabant; $-0.774(p=.003)$, Limburg. Obviously, $\mathrm{IC}_{\text {LOCAL }}$ performs better, a conclusion that might be expected as our $\mathrm{IC}_{\mathrm{LOCAL}}$ is also based on frequencies. It is nevertheless reassuring to see that the frequency of the occurrence of intensifiers overlaps between Dutch corpora, despite the small overlap of intensifiers involved.

Hypothesis 4 predicts preferential orders in intensifier sequences. We compared the IC values in the different positions of the intensifiers adjacent to the adjective. In Table 3 we evaluate the IC values of the three intensifier positions in terms of violating the prediction or otherwise. We compared the three positions pairwise. The percentages matched the preferential patterns predicted by our hypothesis.

Overall, we observe a strong tendency in Table 3 for the $\mathrm{IC}_{\text {TRANs }}$ and $\mathrm{IC}_{\mathrm{LOCAL}}$ values to occur in the order predicted. The figures are more positive for $\mathrm{IC}_{\mathrm{LOCAL}}$, with $8.5 \%$ violations, than for $\mathrm{IC}_{\mathrm{TRANS}}$, with $17.0 \%$ violations. In our data, stacks of three intensifiers occur in just 25 out of 3774 tweets.

T A B LE 3. IC TRANS values are predicted to decrease and $I C_{L O C A L}$ values are predicted to increase the closer an intensifier is to the adjective; 'yes' means that the two values involved have the predicted order, 'no' means a violation

\begin{tabular}{|c|c|c|c|c|c|c|}
\hline \multirow{2}{*}{$\frac{\text { pattern }}{\text { INT position }}$} & \multicolumn{3}{|l|}{ trans } & \multicolumn{3}{|c|}{ local } \\
\hline & yes & no & $\%$ correct & yes & no & $\%$ correct \\
\hline 1 versus 2 & 19 & 4 & $82.6 \%$ & 15 & 8 & $65.2 \%$ \\
\hline 1 versus 3 & 16 & 7 & $69.6 \%$ & 15 & 8 & $65.2 \%$ \\
\hline 2 versus 3 & 424 & 85 & $83.3 \%$ & 476 & 31 & $93.9 \%$ \\
\hline Total & 469 & 96 & $83.0 \%$ & 506 & 47 & $91.5 \%$ \\
\hline
\end{tabular}


T A B LE 4. Nine triplets violating decreasing $I C_{T R A N S}$ values in triplets of intensifiers

\begin{tabular}{llllll}
\hline INT1 & IC $_{\text {TRANS }}$ & INT2 & IC $_{\text {TRANS }}$ & INT3 & IC $_{\text {TRANS }}$ \\
\hline best wel & 1.063 & heel erg & 0.693 & fucking & 0.972 \\
gewoon & 1.971 & echt & 0.57 & fucking & 0.972 \\
zo beetje & 0 & fucking & 0.972 & top & 0.69 \\
echt & 0.57 & zo & 0.659 & geweldig & 0 \\
echt & 0.57 & heel & 1.036 & heel erg & 0.693 \\
echt & 0.57 & heel & 1.036 & goor & 0.693 \\
echt & 0.57 & zo & 0.659 & onwijs & 0 \\
echt & 0.57 & zo & 0.659 & ziek & 0.496 \\
geniaal & 0.693 & helemaal & 1.209 & geweldig & 0 \\
\hline
\end{tabular}

T ABLE 5. Six triplets violating decreasing $I_{L O C A L}$ values in triplets of intensifiers

\begin{tabular}{llllll}
\hline INT1 & IC $_{\text {LOCAL }}$ & INT2 & IC $_{\text {LOCAL }}$ & INT3 & IC $_{\text {LOCAL }}$ \\
\hline best wel & 6.347 & heel erg & 11.047 & fucking & 4.44 \\
gewoon & 7.24 & echt & 1.025 & fucking & 4.44 \\
zo beetje & 12.047 & fucking & 4.44 & top & 11.047 \\
bb & 12.047 & heel & 5.189 & erg & 7.292 \\
ook wel & 12.047 & echt & 1.025 & super & 4.725 \\
geniaal & 1.047 & helemaal & 8.462 & geweldig & 10.047 \\
\hline
\end{tabular}

Focusing on violations of decreasing $\mathrm{IC}_{\text {TRANS }}$ values within these triplets, there are 9 violating sequences, as illustrated in Table 4.

The nine triplets in Table 4 include the intensifier echt 'really' 6 times: this intensifier had a remarkable position in the scattergram of Figure 1. In addition, there are three intensifiers that are somehow, at the same time, a sort of mitigator: best wel 'best yet', gewoon 'plainly', and zo beetje 'a little bit', which all strengthen the qualification by giving it a relative perspective. For $\mathrm{IC}_{\mathrm{LOCAL}}$ there are 6 triplets violating the predicted increase in their values. These triplets are displayed in Table 5. Four of them occurred in Table 4. Again, we see the occurrence of the same three mitigators mentioned in relation to Table 4. The fourth is ook wel 'too indeed'.

Another remarkable pattern in Table 4 is the triplet echt heel heel erg. The intensifier heel occurs twice, in fact replicating the combination heel erg. Replication is a pattern that frequently occurs in another form in our database, by doubling graphemes. Doublings of graphemes may strengthen the surprisal effect in the following way. If in a message $z o$ is expected, but $z 00$ or $z 000$ occurs, the expressive value, i.e. $\mathrm{IC}_{\mathrm{LOCAL}}$, increases, when we distinguish these patterns as different. This can be seen in the frequencies in our corpus and the $\mathrm{IC}$ values derived from them: $\operatorname{IC}_{\mathrm{LOCAL}}(z o)=2.17, \operatorname{IC}_{\mathrm{LOCAL}}(z o o)=5.84$, 
$\operatorname{IC}_{\text {LOCAL }}(z 000)=5.78, \operatorname{IC}_{\text {LOCAL }}(z o o o o)=6.12, \operatorname{IC}_{\text {LOCAL }}(z o o o o o)=7.14$, $\operatorname{IC}_{\text {LOCAL }}(z o o o o o o)=8.73$, and $\operatorname{IC}_{\text {LOCAL }}(z o o o o o o o)=10.46$. The increase in IC values facilitates combinations such as wauw zooooooo goed, since $\mathrm{IC}_{\mathrm{LOCAL}}(-$ wauw $)=9.46$ and does not violate the principle of ascending ICs: it holds that $\mathrm{IC}_{\text {LOCAL }}($ wauw $)<\mathrm{IC}_{\text {LOCAL }}($ zooooooo $)$. In this example, repetitions of identical graphemes cause a systematic increase of $\mathrm{IC}_{\mathrm{LOCAL}}$. This interpretation suggests that orthographic variants of a specific intensifier can, in contrast to the interpretation in Vandekerckhove and Vercammen (2018), be understood as intensifiers with $\mathrm{IC}_{\mathrm{LOCAL}}$ values higher than the $\mathrm{IC}$ value of the original intensifier.

\section{Discussion and conclusion}

In this paper, the strength of intensifiers was determined by their information values (Hypotheses 1 and 2). The information values were based on intensifiers occurring in a Dutch Twitter corpus. The estimated information values have been confirmed by the outcomes in other studies on Dutch intensifiers (ten Buuren et al., 2018; Vandekerckhove \& Vercammen, 2018), which we take as an empirical validation of our approach.

Strength of intensifiers was broken down into two information measures, i.e., $\mathrm{IC}_{\mathrm{TRANS}}$ and $\mathrm{IC}_{\mathrm{LOCAL}}$, which represent the use and expressive values of intensifiers in our Twitter corpus. Both rankings of the resulting values seem to make sense. Our study confirmed our two first hypotheses: established intensifiers have a high use value, i.e., $\mathrm{IC}_{\text {TRANS, }}$ whereas new, expressive intensifiers have a low $\mathrm{IC}_{\mathrm{LOCAL}}(\mathrm{H} 1$ and $\mathrm{H} 2)$. The distinction between expressive value, i.e., $\mathrm{IC}_{\mathrm{LOCAL}}$, and use value, i.e., $\mathrm{IC}_{\mathrm{TRANS}}$, seems to capture the relationship between bleaching and establishment described by Dahl (1979). The process of getting established typically means that intensifiers become real adverbs carrying only the meaning of intensification (cf. zeer 'very', zo 'so', heel 'wholly', erg 'very'). This process of establishment presupposes a high frequency of use.

Constant and frequent use and a broadening range of combinational options make the use value $\mathrm{IC}_{\text {TRANs }}$ increase. Conversely, they cause the expressive value $\mathrm{IC}_{\mathrm{LOCAL}}$ to decrease and, consequently, both values to correlate negatively. The increase of the use value and decrease of the expressive trigger the bleaching of the intensifiers' original meaning, that is to say, both the expressive value and the use value are achievements of intensifiers of equal semantic and pragmatic relevance. The use of two types of values leads to a paradox/ conflict: an intensifier combines easily with all adjectives and is therefore recognizable and transparent (and is therefore 'bleached'); an intensifier must be powerful, expressive, convincing, and therefore new. 


\section{RICHTER AND VAN HOUT}

There is a clear tendency in $\mathrm{IC}_{\text {TRANS }}$ to deliver the value ' 0 ', that represents non-informativity, for recent and surprising intensifiers. The same, but opposite, trend is evident in $\mathrm{IC}_{\mathrm{LOCAL}}$ : modern and surprising intensifiers are highly informative, while established intensifiers that have undergone bleaching have a low expressive value. $\mathrm{IC}_{\mathrm{LOCAL}}$ is the form of information that we would like to identify as 'strength', in a cognitive sense. It gives a formal basis to the effect of surprisal: the attention of language recipients is higher when facing a surprising intensifier than an expected one. Bleaching is a gradual process that starts with new intensifiers and only gradually takes away their original meaning. That is to say, modern intensifiers may cause surprisal and attract attention: they may unfold a high intensifying effect while still carrying a great deal of the original meaning.

A significant, medium-sized, negative correlation emerged between $\mathrm{IC}_{\mathrm{TRANS}}$ and $\mathrm{IC}_{\mathrm{LOCAL}}$, as claimed in Hypothesis 3 . On the other hand, the scattergram in Figure 1 shows some strong outliers that do obstruct a pure linear interpretation. We observed that bleached intensifiers such as echt 'really' have a lower than expected score because of the high share of transitions with the predicate goed 'good'. These outliers could be the result of a selection bias in our corpus, because our predicates are related to a specific reference: (groups of) people, as the subject of the predicate construction. This can only be tested by using other corpora and/or by widening the constructions in which intensifiers can be used. Another outlier is zo 'so'. Removing both outliers from the set of intensifiers does not significantly improve the correlation between the two IC measures (without echt 'really' and $z o$ 'so': $r=-0.708, p=.000$ (Pearson), $\rho=-0.851, p=.000$ (Spearman) vs. with echt 'really' and $z o$ 'so': $r=$ $-0.63, p=.000$ (Pearson), $\rho=-0.84, p=.000$ (Spearman)). Given the many intensifiers, the sizes of the correlations hardly change after removing these two outliers. It is important to note as well that distinguishing the different graphemic variants of zo 'so' would assign the variants higher $\mathrm{IC}_{\text {TRANS }}$ values, pushing them to the right, non-outlying area.

We selected all words or phrases that had some intensifying function with respect to a predicative adjective. This interpretative selection procedure may produce a rather heterogeneous set of intensifiers which is illustrated by the outliers in Figure 1 such as echt 'really' and zo 'so'. In addition, we see quite different word classes, e.g., the noun moker 'sledgehammer', the adverb zo 'so', the participle fucking and the adjective geniaal 'genius'. Do we need to distinguish different classes? ${ }^{1}$ The majority of intensifiers in the scattergram are degree modifiers. Members of this class can directly modify adjectives and thus tend to have a high $\mathrm{IC}_{\mathrm{LOCAL}}$ value, but a low $\mathrm{IC}_{\mathrm{TRANS}}$ value, as the correlation

[1] One reviewer pleaded for the classification of intensifiers into the three classes degree modifiers, degree heads, and general adverbial modifiers. 
between the two information measures is negative. The intensifier $z o$ 'so', in contrast, has both a low $\mathrm{IC}_{\mathrm{LOCAL}}$ value and a low $\mathrm{IC}_{\mathrm{TRANS}}$ value and as a degree head can occur to the left of degree modifier-adjective combinations. $Z o$ 'so' thus combines with saturated, non-gradable, expressions. The second outlier in the scattergram, i.e., echt 'really', drops even more out of the scattergram cloud and seem to form its own class, as a general adverbial modifier, putting restrictions on the stacking order. On the other hand, our point of departure in Hypothesis 4 was that the stacking order is basically free. Predictions on the stacking order, based on strength, turned out to be valid, but we also observed clear violations. We refrain from calling these violations ungrammatical, but conclude that all sorts of violations are permitted, because the driving forces in using intensifiers are surprisal and unexpectedness.

This conclusion does not preclude that there is a prototypical development of intensifiers over time. New intensifiers may develop from degree modifiers to degree heads and finally to general modifiers. As a result, the position of an intensifier in our scattergram begins to shift from the lower right to the medium left into the areas of the degree head class and finally to the general modifiers class, as has happened with echt 'really'. Class changes may be supported by specific patterns in information values. This needs to be investigated by using more corpora, and by exploring other contexts than the predicative adjective. Given the outcomes of our usage-based approach, we provisionally conclude that intensifier classes are fuzzy.

The positive correlation between frequency and strength observed in ten Buuren et al. (2018) was confirmed in our study for the expressive value of intensifiers, that is, $\mathrm{IC}_{\mathrm{LOCAL}}$, but not for the use value, $\mathrm{IC}_{\mathrm{TRANS}}$ : a surprisal effect and thus a high $\mathrm{IC}_{\mathrm{LOCAL}}$ value is achieved with rare intensifiers. $\mathrm{IC}_{\mathrm{LOCAL}}$ also helps to explain the high expressive value of orthographic variants of intensifiers such as zоооооооо or wauuw. These forms occur infrequently in the corpus and their surprisal effect is high, as intended by the language producer.

We hypothesized (Hypothesis 4) a preference for an increasing amount of information from left to right in combinations or stacks of intensifiers, and predicted that the most surprising and informative intensifiers directly precede the adjective. The data confirmed our hypothesis, and more convincingly so for $\mathrm{IC}_{\mathrm{LOCAL}}$ than for $\mathrm{IC}_{\text {TRANS. }}$ The rationale of our hypothesis was that an established intensifier may be helpful in announcing another intensifier. We also observed that mitigators like best wel 'best yet', gewoon 'plainly', and zo beetje (lit.) 'so little bit' seemed to strengthen the qualification by giving it a relative perspective. This relativization perspective needs further investigation.

The concept of surprisal in information theory corresponds to the concepts of certainty and uncertainty that are integral parts of the linguistic hedges model of Zadeh (1972). Within this theory framework, membership functions define certainty, i.e., probabilities of memberships, for instance, the 
probability that an entity belongs to the set of good things, to the delicious things, to the tall beings, to the young beings, etc. Probabilities of memberships can be narrowed down by a concentration operator that Zadeh integrated as an exponent in membership functions. Concentration operators make the probabilities of memberships smaller. It might be interesting to find out whether this concentration operator can be linked to the way we defined the strength of intensifiers within the framework of information theory.

Finally, it is important to note that the bleaching effect in modern intensifiers is not yet very advanced and at least not completed, so that in these cases the original meaning always constitutes part of the surprisal effect. Taking into account that humans tend to make predictions from contexts when they process natural language (Hale, 2001; Staub \& Clifton, 2006; Levy, 2008), we pose the following principle: if an intensifier is detected in the sentence, the prediction is possible that when the next word is not the predicative adjective, it must be another (stronger) strengthening intensifier. An intensifier may even create a place for introducing new intensifiers (see Vandekerckhove \& Vercammen, 2018), but, crucially, the tendencies of sequences of intensifiers discussed in this paper are not strong enough for violations to lead to ungrammaticality. This means that a sequence like fucking zo echt goed (lit., 'fucking so really good') or even kanker fucking echt goed (lit., 'cancer fucking really good') is not excluded. Such sequences are possible, though rather unusual, in current Dutch language use.

\section{REFEREN CES}

Androutsopoulos, J. (2011). Language change and digital media: a review of conceptions and evidence. In T. Kristiansen Tore \& N. Coupland (eds), Standard languages and language standards in a changing Europe (pp. 145-161). Oslo: Novus.

Cohen Priva, U. (2008). Using information content to predict phone deletion. In N. Abner \& J. Bishop (eds), Proceedings of the 27th West Coast Conference on Formal Linguistics (pp. 90-98). Somerville, MA: Cascadilla Proceedings Project.

Crystal, D. (2001). Language and the Internet. Cambridge: Cambridge University Press.

Dahl, Ö. (1979). Typology of sentence negation. Linguistics 17, 79-106.

Dahl, Ö. (2004). The growth and maintenance of linguistic complexity. Amsterdam / Philadelphia: John Benjamins.

Foolen, A., Wottrich, V. \& Zwets, M. (2016). Gruwelijk interessant: Emotieve intensiveerders in het Nederlands. Unpublished manuscript, Radboud Universiteit Nijmegen. Online https://www.ru.nl/grammarandcognition/people/vm/people/ad_foolen/publications/.

Grondelaers, S., van Hout, R. \& van Halteren, H. (2017). Hun twitteren. Tweets als bron voor onderzoek naar syntactische taalvariatie. In V. De Tier, T. van de Wijngaard \& A. Ghyselen (eds), Taalvariatie en sociale media. (pp. 65-72). Leiden: Stichting Nederlandse Dialecten.

Hale, J. (2001). A probabilistic Earley parser as a psycholinguistic model. Proceedings of NAACL (pp. 1-8). https://doi.org/10.3115/1073336.1073357

Hilte, L., Vandekerckhove, R. \& Daelemans, W. (2018). Expressive markers in online teenage talk: a correlational analysis. Nederlandse Taalkunde 23(3), 293-323.

Levy, R. (2008). Expectation-based syntactic comprehension. Cognition 106, 1126-1177. 


\section{RANKING DUTCH INTENSIFIERS}

Piantadosi, S. T., Tily, H. \& Gibson, E. (2011). Word lengths are optimized for efficient communication. PNAS 108(9), 3526-3529.

Richter, M. \& van Hout, R. (2017). How WIE 'how' as intensifer co-occurs with other intensifiers in German sentences. In R. Loukanova \& K. Liefke (eds), Proceedings of the Workshop on Logic and Algorithms in Computational Linguistics 2017 (LACompLing2017) (pp. 133-135). Stockholm, 16-19 August 2017. Online http://su.diva-portal.org/smash/ record.jsf?pid=diva2:1140018\&dswid=1028.

Shannon, C. E. \& Weaver, W. (1948). A mathematical theory of communication. The Bell System Technical Fournal 27, 379-423, 623-656.

Staub, A. \& Clifton Jr, C. (2006). Syntactic prediction in language comprehension: Evidence from either... or. Fournal of experimental psychology: Learning, memory, and cognition 32(2), $425-436$.

Sweetser, E. E. (1988). Grammaticalization and semantic bleaching. Proceedings of the fourteenth annual meeting of the Berkeley Linguistics Society (pp. 389-405).

Tagliamonte, S. (2008). So different and pretty cool! Recycling intensifiers in Toronto, Canada. English Language and Linguistics 12(2), 361-394.

Tagliamonte, S. (2016). So sick or so cool? The language of youth on the internet. Languagein Society 45(1), 1-32.

ten Buuren, M., van de Groep, M., Collin, S., Klatter, J. \& de Hoop, H. (2018). Facking nice! Een onderzoek naar de intensiteit van intensiveerders. Nederlandse Taalkunde 23, 223-250.

Tjong Kim Sang, E. \& van den Bosch, A. (2013). Dealing with big data: the case of Twitter. Computational Linguistics in the Netherlands Fournal 3, 121-134.

Vandekerckhove, R. \& Vercammen, J. (2018). De regionale en globale dynamiek van versterkers in Vlaamse jongerentaal. In T. Colleman et al. (eds), Woorden om te bewaren: huldeboek voor Facques Van Keymeulen (pp. 699-712). Gent.

Zadeh, L. (1972). A fuzzy-set-theoretical interpretation of linguistic hedges. Fournal of Cybernetics 2, 4-34. 
RICHTER AND VAN HOUT

\section{Appendix 1}

The complete set of intensifiers with their $\mathrm{IC}_{\text {TRANS}}$-values

\begin{tabular}{|c|c|c|c|c|c|c|c|}
\hline \multirow{3}{*}{$\begin{array}{l}\text { Int } \\
\text { abnormal } \\
\text { bb }\end{array}$} & \multicolumn{2}{|c|}{$\mathrm{IC}_{\text {TrANS }}$ Int } & \multicolumn{2}{|c|}{$\mathrm{IC}_{\text {TrANS }}$ Int } & \multicolumn{2}{|c|}{$\mathrm{IC}_{\text {TRANS. Int }}$} & \multirow{2}{*}{$\frac{\mathrm{IC}_{\text {TRANS }}}{1.408}$} \\
\hline & 0 & geweldig & 0 & ma pang & 0 & te & \\
\hline & 0 & gewoon & 1.971 & main & 0 & tering & 0.856 \\
\hline beetje & 1.609 & goed & 1.3 & mega & 0.556 & top & 0.693 \\
\hline belachelijk & 0 & goor & 0.693 & mie & 0 & tyfus & 0 \\
\hline best & 0.426 & grappig & 0 & misselijk & 0 & uber & 0.693 \\
\hline best wel & 1.063 & gruwelijk & 0 & moker & 0 & veel & 0.963 \\
\hline boem & 0 & hard & 0 & niet normaal & 0 & veel ste & 0 \\
\hline boeng & 0.693 & hartstikke & 0 & niet zo & 0 & verkakt & 0 \\
\hline damn & 0.693 & hayeck & 0 & oming & 0.746 & vet & 0.644 \\
\hline dik & 1.099 & heel & 1.036 & ongelooflijk & 0 & vetmelig & 0 \\
\hline dodelijk & 0 & heel erg & 0.693 & onmogelijk & 0 & vettig & 0 \\
\hline donders & 0.693 & helemaal & 1.209 & ontzettend & 0.665 & vies & 0.693 \\
\hline dood & 0.839 & $\begin{array}{c}\text { helemaal } \\
\text { niet }\end{array}$ & 1.149 & onwijs & 0 & vrij & 0 \\
\hline echt & 0.570 & hoe & 0.693 & ook wel & 0 & wat & 0.693 \\
\hline echt niet & 1.218 & hopi & 0 & overdreven & 0 & wauw & 0.665 \\
\hline echt wel & 0.778 & insane & 0 & paolo & 0 & we & 0.693 \\
\hline een beetje & 0 & irritant & 0 & pas & 0 & wel & 0 \\
\hline eigenlijk & 0 & kaka & 0 & perfect & 0 & wreed & 0 \\
\hline enorm & 0.693 & kanker & 1.698 & pittig & 0.866 & zeer & 0.963 \\
\hline erg & 1.827 & kaolo & 0.501 & puur & 0 & zeker & 1.099 \\
\hline faal & 0 & kapot & 0.665 & ranzig & 0 & $\begin{array}{r}\text { zeker } \\
\text { wel }\end{array}$ & 0 \\
\hline fake & 0 & kaulo & 1.378 & redelijk & 0 & ziek & 0.496 \\
\hline fantastisch & 0 & kei & 0.931 & rete & 0 & ziekelijk & 0.418 \\
\hline favoriet & 0 & killer & 0 & reuze & 0 & zielig & 0 \\
\hline flink & 0 & knap & 0 & schijnheilig & 0 & zo & 0.659 \\
\hline fucking & 0.972 & knetter & 0 & sexy & 0 & zo beetje & 0 \\
\hline gaaf & 0 & kut & 0 & super & 0.7 & $\mathrm{zu}$ & 0 \\
\hline geniaal & 0.693 & lekker & 1.946 & $\begin{array}{l}\text { super de } \\
\text { puper }\end{array}$ & 0 & zwaar & 1.946 \\
\hline gevaarlijk & 0 & lomp & 0 & tantoe & 0 & & \\
\hline
\end{tabular}




\section{Appendix 2}

The complete set of intensifiers with their $\mathrm{IC}_{\mathrm{LOCAL}}$-values

\begin{tabular}{|c|c|c|c|c|}
\hline Int & $\mathrm{IC}_{\mathrm{LOCAL}}$ Int & $\mathrm{IC}_{\text {LOCAL }}$ Int & $\mathrm{IC}_{\mathrm{LOCAL}}$ Int & $\mathrm{IC}_{\text {LOCAL }}$ \\
\hline abnormal & 12.047 geweldig & 10.047 ma pang & 12.047 te & 6.762 \\
\hline $\mathrm{bb}$ & 12.047 gewoon & 7.240 main & 12.047 tering & 9.240 \\
\hline beetje & 9.725 goed & 8.588 mega & 9.047 top & 11.047 \\
\hline belachelijk & 12.047 goor & $11.047 \mathrm{mie}$ & 11.047 tyfus & 12.047 \\
\hline best & 5.897 grappig & 12.047 misselijk & 12.047 uber & 11.047 \\
\hline best wel & 6.347 gruwelijk & 12.047 moker & 12.047 veel & 9.462 \\
\hline boem & 12.047 hard & 12.047 niet normaal & 8.877 veel ste & 12.047 \\
\hline boeng & 11.047 hartstikke & 12.047 niet zo & 11.047 verkakt & 12.047 \\
\hline damn & 11.047 hayeck & 11.047 oming & 9.725 vet & 6.214 \\
\hline dik & 10.462 heel & 5.189 ongelooflijk & 11.047 vetmelig & 12.047 \\
\hline dodelijk & 12.047 heel erg & 11.047 onmogelijk & 12.047 vettig & 12.047 \\
\hline donders & 11.047 helemaal & 8.462 ontzettend & 9.462 vies & 11.047 \\
\hline dood & 9.047 helemaal niet & 9.725 onwijs & 10.047 vrij & 12.047 \\
\hline echt & 1.025 hoe & 11.047 ook wel & 12.047 wat & 11.047 \\
\hline echt niet & 8.462 hopi & 12.047 overdreven & 12.047 wauw & 9.462 \\
\hline echt wel & 8.240 insane & 12.047 paolo & 12.047 we & 11.047 \\
\hline een beetje & 12.047 irritant & 12.047 pas & 12.047 wel & 12.047 \\
\hline eigenlijk & 12.047 kaka & 12.047 perfect & 12.047 wreed & 11.047 \\
\hline enorm & 11.047 kanker & 6.838 pittig & 10.047 zeer & 9.462 \\
\hline erg & 7.292 kaolo & 9.462 puur & 12.047 zeker & 10.462 \\
\hline faal & 12.047 kapot & ranzig & 12.047 zeker wel & 12.047 \\
\hline fake & 12.047 kaulo & redelijk & 12.047 ziek & 7.403 \\
\hline fantastisch & 12.047 kei & 5.780 rete & 12.047 ziekelijk & 10.047 \\
\hline favoriet & 12.047 killer & 12.047 reuze & 12.047 zielig & 12.047 \\
\hline flink & 12.047 knap & 12.047 schijnheilig & $12.047 \mathrm{zo}$ & 2.174 \\
\hline fucking & 4.440 knetter & 12.047 sexy & 12.047 zo beetje & 12.047 \\
\hline gaaf & $12.047 \mathrm{kut}$ & 12.047 super & $4.425 \mathrm{zu}$ & 12.047 \\
\hline geniaal & 11.047 lekker & 9.240 super de puper & 11.047 zwaar & 9.240 \\
\hline gevaarlijk & 12.047 lomp & 12.047 tantoe & 12.047 & \\
\hline
\end{tabular}

